\title{
Modification of the technique of osteotomy for surgical maxillary
}

\section{expansion}

João Luis Carlini ${ }^{1}$, Cristina Rieth ${ }^{2}$, Danielle Del Santo Severo ${ }^{2}$, Kesia Keiko Asami ${ }^{2}$

${ }^{1}$ Oral and Maxillofacial Surgery, Chief of Stomatology Departament, Professor at Federal University of Paraná, Staff of CAIF - Center for Integral Assistance of Cleft Lip and Palate Patients, Curitiba, Paraná, Brazil

${ }^{2}$ Dental Surgeon, School of Dental Medicine at Federal University of Paraná, Curitiba, Paraná, Brazil

\section{Abstract}

Surgically assisted maxillary expansion is a technique used to correct transverse maxillary deficiency, which is a dentofacial anomaly related to the decrease of the upper arch over the lower arch. It is applied to patients in their late teens and adults due to skeletal maturity, causing obliteration of the intermaxillary suture, which requires orthodontic procedure, associated with surgery. The purpose of this study is to report the clinical case of a patient admitted for surgical maxillary expansion through the modified technique and point out the possible advantages, such as aesthetics maintenence, long-term stability, faster return to orthodontic treatment, and improved bone healing. However, there are some contraindications when the patient presents severe crowding, roots of the canine and lateral incisor are converging and in patients who will undergo to protraction with facial mask.

\section{Introduction}

The transverse maxillary deficiency has a multifactorial etiology, and it is associated with functional and aesthetic commitment. The diagnosis is established through clinical exams, X-rays, and model study [1].

The patients who need orthodontic and/or surgical maxillary expansion frequently present a typical vertical pattern: long facial height anterior inferior, high palate, low tongue posture, incompetent lips, and mouth breathing [2], unilateral or bilateral cross bite, and anterior crowding [3-6].

The maturity of the patient's skeleton and the amount of expansion expected are crucial to choose the technique to be performed to correct the transverse discrepancy jaw $[3,7,8]$. Another relevant aspect to be assessed is the magnitude of the transverse jaw discrepancy [4-6].

Following Hass (1980), in order to correct the atresia skeletal jaw, it is necessary a treatment that does not only move teeth, but changes the position of the alveolar bone processes, teeth, and consequently the jaw segments.

The rapid maxillary expansion (RME), using breakers only, is one of the techniques indicated to treat transversal maxillary deficiency orthopedic and it has a history over 145 years. Introduced by Angell $[10,11]$, it allows the treatment of transversal discrepancy in skeletally immature patients $[3-6,12,13]$ trough the power emitted by the expander, opening the palatal suture and making the jaw expand [12].

In adult patients, who have transverse maxillary hypoplasia unilateral or bilateral, the effective
Citation: Carlini J, Rieth C, Severo D, Asami K. (2015) Modification of the technique of osteotomy for surgical maxillary expansion. Dentistry 3000. 1:a001 doi:10.5195/d3000.2015.37 Received: July 29, 2015

Accepted: September 17, 2015

Published: October 23, 2015

Copyright: (C2015 Carlini J, Severo D, Asami K. This is an open access article licensed under a Creative Commons Attribution Work 4.0 United States License.

Email: kka12@pitt.edu form of treatment is the surgically assisted rapid maxillary expansion (SARME), a combination of orthodontics and surgery. Because of skeletal maturity, there is an increase in secondary bone interdigitation, and fusion of palatal suture $[4-8,13,14]$. This procedure releases the resistance sites $[4-8,10,12$,

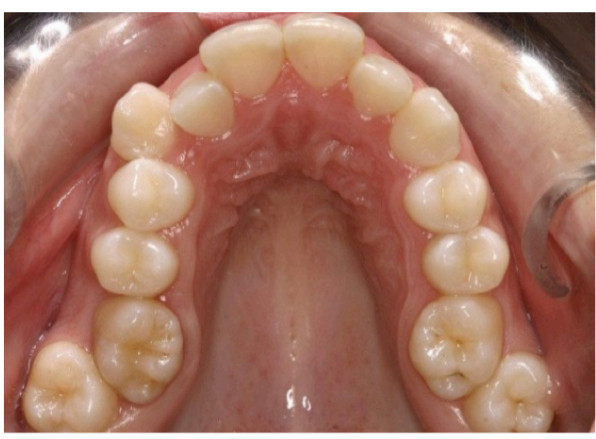

Figure 1. Occlusal view of the patient with transverse maxillary deficiency

$15,16]$. 


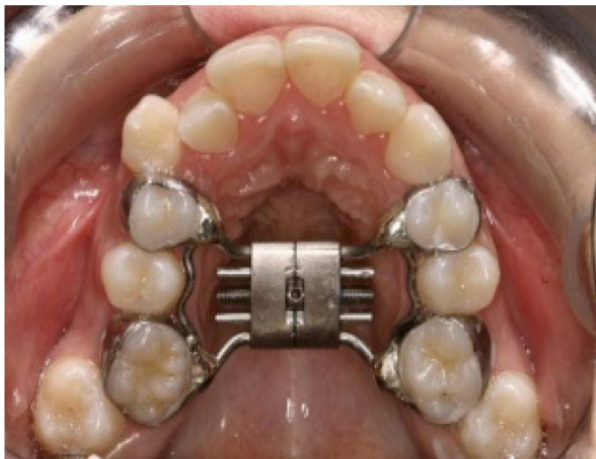

Figure 2. Hyrax breaker installed with support only on teeth

The purpose of this paper is to assess the efficiency of the surgical technique modification, demonstrated with a case report, in which the osteotomy is performed between the lateral incisors and canines, Fig. 5. Performing the modified technique, it was possible to analyze several positive aspects, such as: increased stability of the correction in long term, optimized bone healing due to the increased production of calluses, faster return to orthodontics treatment, minimum periodontal hazard, it prevents the shift of the midline, and the aesthetic is maintained by splitting the diastema generated in two points, as you can see in Fig. 9 Different from the conventional technique, where the diastema is single and between central incisors, as it is shown in Fig. 9.

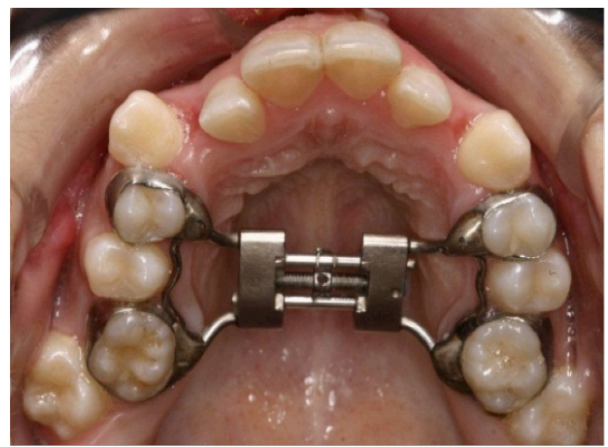

Figure 3. Postoperative SARME. Occlusal view showing the diastemas between the canine and lateral incisor Case Report
Female patient, 23 years old, was referred by her orthodontist with transverse maxillary deficiency, illustrated in Fig. 1. The diagnosis was based on X- rays, Fig. 8, clinical exam and evaluation of plaster models. A Hyrax expander was used for one week to try to open the palatal bone suture without surgery, but it failed (Fig. 2).

The patient was submitted to pre-operative routine laboratory tests; blood tests, electrocardiogram, chest X-ray, and also a pre anesthetic consultation, then she was released. She was admitted on the day of surgery, under general anesthesia and nasotracheal intubation. The surgery went as follows: in the back of the vestibule, it was incised with 15 scalpel blades, extending from the second pre molar until the second pre molar contralateral. After detached the periosteum, the pyriform aperture and the zygomatic pillar were exposed. Then the nasal mucous membrane was detached and tunneled to the posterior region until the maxillary tuberosity, where the reverse retractor Langenbeck was adapted. Protecting the nasal mucosa, with shifter Molt the osteotomy with reciprocating saw was performed; starting from the tuberosity, a section was made $5 \mathrm{~mm}$ above the roots of the teeth. The osteotomy was performed on the entire side wall of the maxillary sinus and the region of the piriform aperture, being bicortical, Fig 4 . Using the curved chisel, it promoted the separation of the blade pterygoid of the tuberosity of the maxilla. With a single guide chisel, the medial wall of the maxillary sinus was broken and with the double guide chisel, the nasal septum was separated. Then the flap was displaced in the region between the canine and the lateral incisor until the inserted gingiva, tunneling until the cervical of the teeth was per- formed. Using the reciprocating saw, the osteotomy was done with a blade of $0.5 \mathrm{~mm}$ thick, illustrated in Fig. 5, leaving from the piriform aperture toward the cervical of the teeth, protecting the palatal mucosa with the index finger. The osteotomy extended about $5 \mathrm{~mm}$ below the alveolar crest interdental, seen in Fig. 6. For subsequent region, after detaching the nasal mucosa, the reciprocating saw was in the most posterior position, then the osteotomy was complemented with a straight chisel to the posterior edge of the jaw. Similarly, we use the chisel to complete the osteotomy between the teeth, always protecting the palatal mucosa and then it was taken into occlusion to observe the positioning of the teeth. The breaker was activated to observe if the expansion occurred symmetrically, as shown in Fig. 7. If this was not happening, it would be important go over the chisel in all osteotomies. The screw breaker was turned off and we sutured the

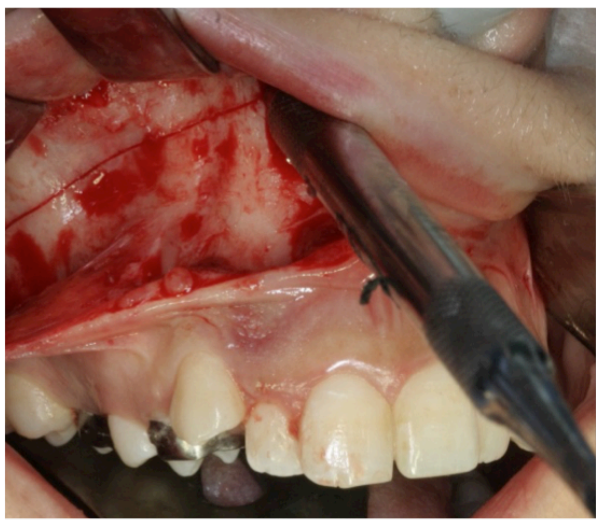

Figure 4. Surgical access and osteotomy. Le Fort I. $5 \mathrm{~mm}$ above the roots (right side)

wound with wire vicryl 4-0.

The time of surgery was 50 minutes, and the patient was discharged the same day. The postoperative care consisted of ice packs on the face, three days of a liquid diet, followed by pasty-liquid, saline solution for cleaning, and anti- 


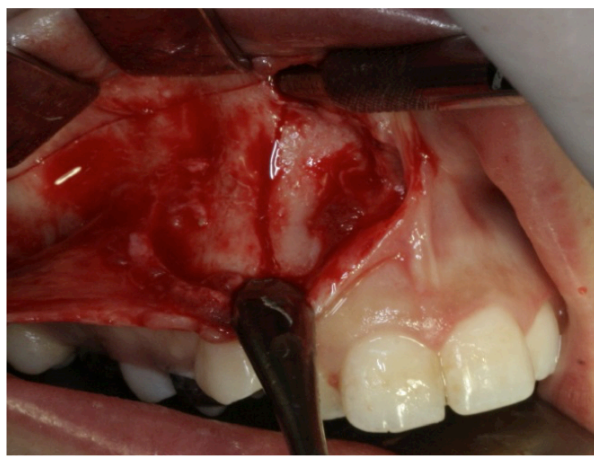

Figure 5. Osteotomy between the canine and lateral incisor teeth (right side)

inflammatory and analgesic for three days. After seven days the patient was re-evaluated in the clinic and she started activating the breaker, with activation $1 / 4$ turn in the morning and $1 / 4$ turn in the afternoon. After a week the patient was referred to the orthodontist to control the extent of maxillary expansion.

The control of bone healing was performed by occlusal radiographs. After 30 days, seen in Fig. 8, and after three months, which callus formation was observed. Then the orthodontist removed the breaker and began the orthodontic treatment, Fig. 8 and Fig 9. No sequel was observed after surgery, such as gingival retraction, tooth roots injury, no bone callus formation or recurrence that could compromise the result.

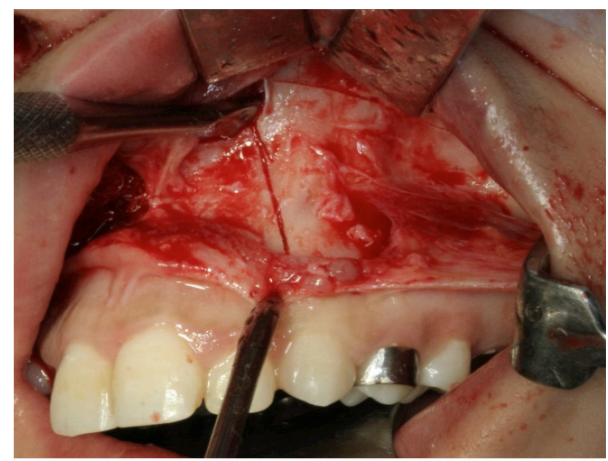

Figure 6. Vertical Osteotomy from the piriform aperture toward toward the cervical of the teeth

The measurement was performed on plaster models, preoper- atively and postoperatively, using calibrated caliper. We analyzed the interdental distances between central fossae of the upper first molars and the palatal portion of the upper canines, Table 1.

\section{Discussion}

The success of treatment depends on correct diagnosis, anatomical knowledge and selection of the correct technique. To treat adult patients with maxillary atresia, surgically assisted disjunction has demonstrated excellent results as a complementary method to orthodontic treatment, where the surgery is to relieve the resistance of bone structure to the expansive forces.

There are several authors who describe the techniques for rapid maxillary expansion. These techniques are diversified according to age, advocated osteotomies, local aspects, etc [12]. Age is a factor to be considered before performing the surgical expansion because with increasing age, the probability of decrease in the bone support is higher and thus the power emitted by the expander is not transmitted to the intermaxillary bone or other skeletal structure, but for teeth, that may cause extrusion of teeth, and the skeletal expansion is reduced [17].

Although there is no consensus regarding the extension of the surgery, the vast majority of authors cite the nasomaxillary, palatine, and zigomaticomaxilar osteotomies as indispensable. However, pterygomaxillary disjunction is not always included [16]. Seeberger et al. (2010) concluded in his work that even without the pterygomaxillary disjunction, it is possible to achieve an expansion with stable bite. Laudemann et al. (2009, 2010, 2011) mentioned that this maneuver can be potentially dangerous and can lead intra- and extracranial complications such as severe bleeding or injury of the internal jugular vein or the internal carotid artery, caused by displaced fragments of the pterygoid plate or by the chisel during pterygomaxillary disjunction.

Regarding the technique, in this study we chose the modified technique, in which the osteotomy is performed between the lateral incisors and canines, instead of between the central incisors. Even though we performed the pterygomaxillary disjunction, there were no complications regarding this maneuver.

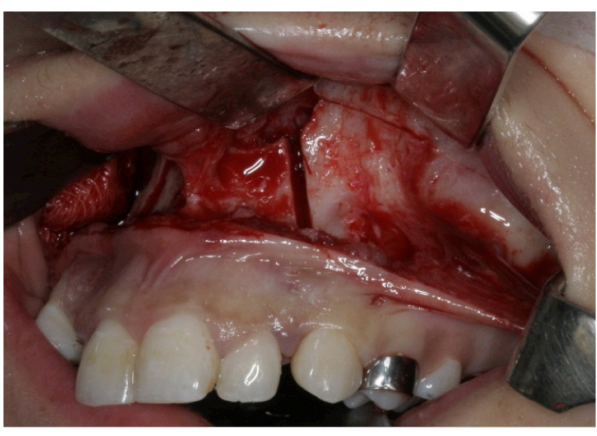

Figure 7 . The breaker activation to observe if the expansion occurred symmetrically evidenced by bone diastases

In the study of Landes et al. $(2009,2012)$, the minimum distance between the roots of the lateral incisors and canines with 95\% reliability to perform the modified technique was $1.4 \mathrm{~mm}$, however, in clinical practice it has been observed that with a measure of 1.2 $\mathrm{mm}$ is already possible to perform modified technique of maxillary expansion without major damage. In the present study the distance of $1 \mathrm{~mm}$ was considered safe to perform the procedure. That is because the reciprocating saw blades are $0.5 \mathrm{~mm}$, and the visualization of the root protuberances, especially the canines, assist in the location of the osteotomy. 
a.

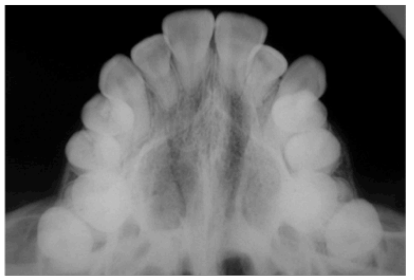

b.

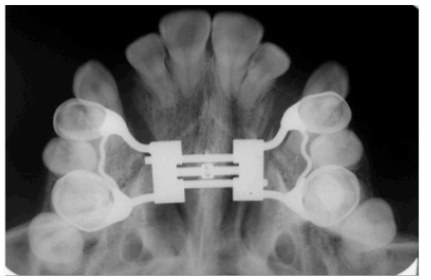

C.

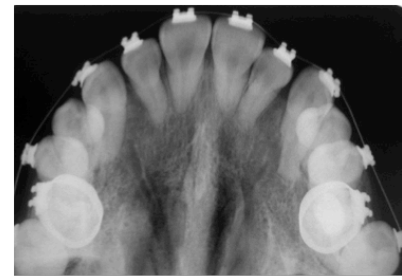

used the Hyrax expander for ease of cleaning, less compression of the palatal mucosa, and the fact that osteotomies were checked to observe possible points of resistance.

General anesthesia, as cited Alfaro et al. (2010), is classically advocated for perdays post-operative $c$. Three months callus formation can be observed

Landes et al. $(2009,2012)$ used the piezo device in their study, arguing there was less damage to the tooth roots, compared to reciprocating saw that we used in this study. We believe it is a great option for the execution of this technique because the piezo is much less traumatic. However the time for the execution is much higher when compared with the reciprocating

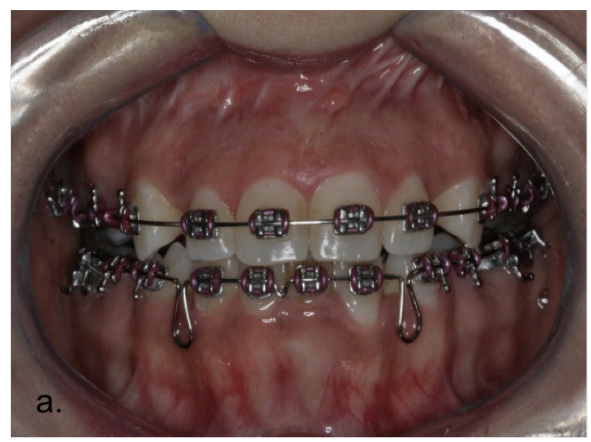

Other advantage of the surgical maxillary expansion is that it provides the patient an enlargement of the nasal air passages, due to lateral repositioning of the lateral nasal walls, thereby improving nasal breathing $[7,8,14,18]$. In this study the patient had significant improvement in breathing after being submitted to maxillary expansion surgery.

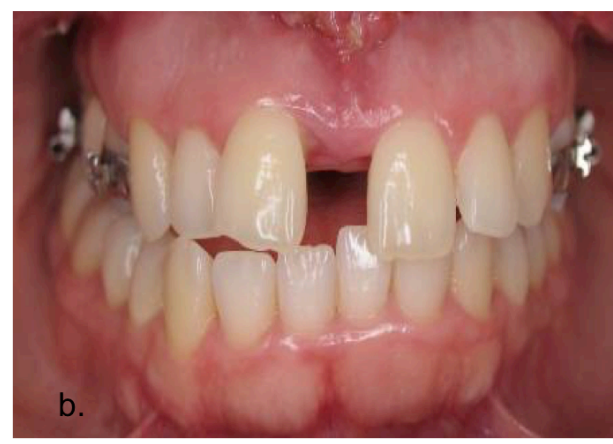

Figure 9. a. Post-operative occlusion view of the modified technique b. Postoperative occlusion view of the conventional technique saw, but this depends on the surgeon's skill. According to Gauthier et al. (2001), the surgical maxillary expansion, when it releases the resistance between the intermaxillary suture, produces minimum periodontal hazard. In the present study, the same conclusion was found. It is worth remembering that the patients who underwent surgery had a healthy periodontal condition and sufficient posterior dental support. However, Sanromán et al. (2010) mentioned that tailored devices are an alternative to a stable expansion achieved in adult patients who have poor periodontal quality and low posterior dental support.
Similar to the work of Anttila et al. (2004), in this study the patient succeeded in transverse maxillary expansion. Another important observation of Anttila et al. (2004) that was also observed in this study is the fact that the support bone of teeth must not be compromised, this being so, it is a prerequisite to achieve success in this surgical procedure.

Another factor to be considered is the type of breaker. Hyrax breaker can increase the pressure on the teeth because the support is only on the teeth. When opting for Hass breaker, where there is also a support in the palatal mucosa, this issue is minimized. In this case we forming the SARME, since pterygomaxillary disjunction becomes potentially traumatic to the patient; it is performed only with sedation. For this reason, in this study, all surgical procedures were performed with patients under general anesthesia.

It is important to note that comparisons between dimensions achieved through the expansion of a study and another are irrelevant, since the requirements may vary from patient to patient. What is relevant is to obtain an adequate expansion to correct a cross bite or any other occlusal patient's need in a specific case [19].

\section{Conclusion}

Surgically Assisted Rapid Maxillary Expansion has proven to be an effective and reliable technique to treat maxillary transverse deficiency in adolescent and adult patients. SARME has shown several advantages, such as a stable procedure, with minimum periodontal hazard; improved aesthetics seen in the immediate post-operative, by splitting the diastema generated in two points; early return for orthodontic treatment, and improved nasal breathing. 
Table 1. Canine / Molar Relation

\begin{tabular}{|c|c|c|}
\hline & Pre-operative & Post-operative \\
\hline Canine & $24 \mathrm{~mm}$ & $29 \mathrm{~mm}$ \\
\hline Molar & $25 \mathrm{~mm}$ & $34 \mathrm{~mm}$ \\
\hline
\end{tabular}

\section{References}

1. Avaliação clínica dos procedimentos de expansão cirurgicamente assistida da maxila (ECAM). Clinical evaluation of surgically assisted maxillary expansion (SAME). Paulo Domingos Ribeiro Jr.I; Eduardo Sanches GonçalesII; Paulo César Ulson de SouzalII; Hugo Nary FilhoIV; João Gualberto Cerqueira LuzV . Rev. Dent. Press Ortodon. Ortop. Facial vol.11 no.1 Maringá Jan./Feb. 2006. Paulo Domingos Ribeiro Jr.I; Eduardo Sanches GonçalesII

2. Nasal cavity size, airway resistance, and subjective sensation after surgically assisted rapid maxillary expansion: a prospective longitudinal study. Magnusson A, Bjerklin K, Nilsson P, Jönsson F, Marcusson A. Am J Orthod Dentofacial Orthop. 2011 Nov;140(5):641-51. doi: 10.1016/j.ajodo.2010.11.024. PMID: 22051484

3. Periodontal effects of surgically assisted rapid palatal expansion evaluated clinically and with cone-beam computerized tomography: 6-month preliminary results. Gauthier C, Voyer R, Paquette M,
Rompré P, Papadakis A. Am J Orthod Dentofacial Orthop. 2011 Apr;139(4 Suppl):S117-28. doi: 10.1016/j.ajodo.2010.06.022. PMID: 21435529

4. Evaluation of surgically assisted rapid maxillary expansion with or without pterygomaxillary disjunction based upon preoperative and post-expansion 3D computed tomography data. Laudemann K, Petruchin O, Mack MG, Kopp S, Sader R, Landes CA. Oral Maxillofac Surg. 2009

Sep;13(3):159-69. doi: 10.1007/s10006-009-0167-3. PMID: 19714376

\section{Long-term 3D cast model} study: bone-borne vs. tooth-borne surgically assisted rapid maxillary expansion due to secondary variables. Laudemann K, Petruchin O, Nafzger M, Ballon A, Kopp S, Sader RA, Landes CA. Oral Maxillofac Surg. 2010 Jun;14(2):105-14. doi: 10.1007/s10006-009-0194-0. PMID: 20108107

6. Assessment of surgically assisted rapid maxillary expansion regarding pterygomaxillary disjunc tion using thin volume-rendering technique: in variance analysis and in reliability, accuracy, and validity. Laudemann K, Santo G, Revilla C, Harth M, Kopp S, Sader RA, Landes CA. J Oral Maxillofac Surg. 2011 Oct;69(10):2631-43. doi: 10.1016/j.joms.2010.12.007. Epub 2011 Apr 7. PMID: 21474227

\section{Comparison of bipartite} versus tripartite osteotomy for maxillary transversal expansion using 3-dimensional preoperative and postexpansion computed tomography data. Landes CA, Laudemann K, Petruchin O, Mack MG, Kopp S, Ludwig B, Sader RA, Seitz O. J Oral Maxillofac Surg. 2009 Oct;67(10):2287-301. doi: 10.1016/j.joms.2009.04.069. PMID: 19761925

8. $\quad$ Advantages and limits of 3segment (paramedian) versus 2segment (median) surgically assisted rapid maxillary expansion (SARME). Landes CA, Laudemann K, Petruchin O, Revilla C, Seitz O, Kopp S, Ludwig B, Sader RA. Oral Surg Oral Med Oral Pathol Oral Radiol. 2012 Jan;113(1):29-40. doi: 10.1016/j.tripleo.2011.01.013. 
Epub 2011 Mar 31. PMID: 22677689

9. Long-term posttreatment evaluation of rapid palatal expansion. Haas AJ. Angle Orthod. 1980 Jul;50(3):189-217. No abstract available. PMID: 6996533

10. Stability in dental changes in RME and SARME: a 2-year followup. Sokucu O, Kosger HH, Bicakci AA, Babacan H. Angle Orthod. 2009 Mar;79(2):207-13. doi: 10.2319/031808-155.1. PMID: 19216605

11. Surgically assisted rapid maxillary expansion: a comparison of technique, response, and stability. Northway WM, Meade JB Jr. Angle Orthod. 1997;67(4):309-20. PMID: 9267580

12. Minimally invasive surgically assisted rapid palatal expansion with limited approach under sedation: a report of 283 consecutive cases. Hernandez-Alfaro F, Mareque Bueno J, Diaz A, Pagés CM. J Oral Maxillofac Surg. 2010

Sep;68(9):2154-8. doi: 10.1016/j.joms.2009.09.080. Epub 2010 Jul 2. PMID: 20584567

13. Surgically assisted rapid palatal expansion (SARPE). Goddard R, Witherow H. Br J Oral Maxillofac Surg. 2011 Jan;49(1):65-6. doi: 10.1016/j.bjoms.2009.11.013. Epub 2010 Feb 18. No abstract available. PMID: 20170994

14. Transverse maxillary distraction in patients with periodontal pathology or insufficient tooth anchorage using custom-made devices. Fernández-Sanromán J, Do- nascimento MG, López AC, Ferro MF, Berrondo IA. J Oral Maxillofac Surg. 2010 Jul;68(7):1530-6. doi: 10.1016/j.joms.2009.09.074. Epub 2010 Apr 22. PMID: 20417007

15. Long term effects of surgically assisted rapid maxillary expansion without performing osteotomy of the pterygoid plates. Seeberger R, Kater W, Davids R, Thiele OC. J Craniomaxillofac Surg. 2010 Apr;38(3):175-8. doi: 10.1016/j.jcms.2009.07.003. Epub 2009 Aug 5. PMID: 19660962

16. Changes in nasopharyngeal airway following orthopedic and surgically assisted rapid maxillary expansion. Kurt G, Altuğ-Ataç AT, Atac MS, Karasu HA. J Craniofac Surg. 2010 Mar;21(2):312-7. doi: 10.1097/SCS.0b013e3181cf5f73. PMID: 20186094

17. Feasibility and long-term stability of surgically assisted rapid maxillary expansion with lateral osteotomy. Anttila A, Finne K, KeskiNisula K, Somppi M, Panula K, Peltomäki T. Eur J Orthod. 2004 Aug;26(4):391-5. PMID: 15366383

18. Changes in nasal volume after surgically assisted bone-borne rapid maxillary expansion. Deeb W, Hansen L, Hotan T, Hietschold V, Harzer W, Tausche E. Am J Orthod Dentofacial Orthop. 2010 Jun;137(6):782-9. doi: 10.1016/j.ajodo.2009.03.042. PMID: 20685533

19. Correção das deficiências transversas e ântero-posteriores da maxila em pacientes adultos / Maxillary anteroposterior and trans- verse problems correction in adult patients. Carlini, João Luiz; Biron, Cássia; Gomes, Kelston Ulbricht; Gebert, Andréa; Strujak, Guilherme. Rev. dent. press ortodon. ortopedi. facial; 12(5): 92-99, set.-out. 2007. ilus, tab. Artigo em Português | LILACS | ID: lil-465909. 